\title{
Experimental and Computational Modal Analyses for Launch Vehicle Models considering Liquid Propellant and Flange Joints
}

\author{
Chang-Hoon Sim, ${ }^{1}$ Geun-Sang Kim, ${ }^{1}$ Dong-Goen Kim, ${ }^{1}$ In-Gul Kim, ${ }^{1}$ Soon-Hong Park, ${ }^{2}$ \\ and Jae-Sang Park $\left(\mathbb{1}^{1}\right.$ \\ ${ }^{1}$ Department of Aerospace Engineering, Chungnam National University, Daejeon 34134, Republic of Korea \\ ${ }^{2}$ Launcher Structures and Materials Team, Korea Aerospace Research Institute, Daejeon 34133, Republic of Korea \\ Correspondence should be addressed to Jae-Sang Park; aerotor@cnu.ac.kr
}

Received 25 July 2017; Accepted 24 October 2017; Published 17 January 2018

Academic Editor: Ratneshwar Jha

Copyright ( 92018 Chang-Hoon Sim et al. This is an open access article distributed under the Creative Commons Attribution License, which permits unrestricted use, distribution, and reproduction in any medium, provided the original work is properly cited.

\begin{abstract}
In this research, modal tests and analyses are performed for a simplified and scaled first-stage model of a space launch vehicle using liquid propellant. This study aims to establish finite element modeling techniques for computational modal analyses by considering the liquid propellant and flange joints of launch vehicles. The modal tests measure the natural frequencies and mode shapes in the first and second lateral bending modes. As the liquid filling ratio increases, the measured frequencies decrease. In addition, as the number of flange joints increases, the measured natural frequencies increase. Computational modal analyses using the finite element method are conducted. The liquid is modeled by the virtual mass method, and the flange joints are modeled using onedimensional spring elements along with the node-to-node connection. Comparison of the modal test results and predicted natural frequencies shows good or moderate agreement. The correlation between the modal tests and analyses establishes finite element modeling techniques for modeling the liquid propellant and flange joints of space launch vehicles.
\end{abstract}

\section{Introduction}

Liquid propulsion launch vehicles are widely used because of their high specific impulse and easy control of thrust, despite their drawbacks such as combustion instability, complicated structure, and high production cost. The natural frequencies of space launch vehicles using liquid propellant change during flight because liquid propellant is rapidly consumed. This change in natural frequencies has a significant influence on the dynamics, loads, and vibration characteristics of launch vehicles.

Modal tests are usually used to investigate the modal characteristics (natural frequencies and mode shapes) of launch vehicles, but they are inefficient in terms of time and manpower. Recently, computational modal analyses using an advanced finite element (FE) method have been used to replace or assist modal tests for launch vehicles. However, it is not easy to establish the FE modeling techniques for the computational modal analysis of space launch vehicles that contain liquid propellant.

Modal tests for the full-scale model of the Atlas-Centaur were conducted with various propellant levels in order to consider different flight conditions [1]. However, modal analyses were not performed. Although modal tests and analyses were performed for the KSR- (Korean Sounding Rocket-) III, the FE model using one-dimensional beam elements for modal analysis did not consider the liquid propellant [2]. For the ARES I-X, the launch vehicle was divided into several subparts and modal tests and analyses were conducted for each part, but these did not account for the liquid propellant in the second stage [3]. Although modal tests and analyses for simple cylinders filled with liquid have been performed recently [4-7], most studies used single cylindrical structures filled with liquid (water). Modal analyses and tests for cylindrical structures with multiple sections containing liquid have rarely been conducted. 


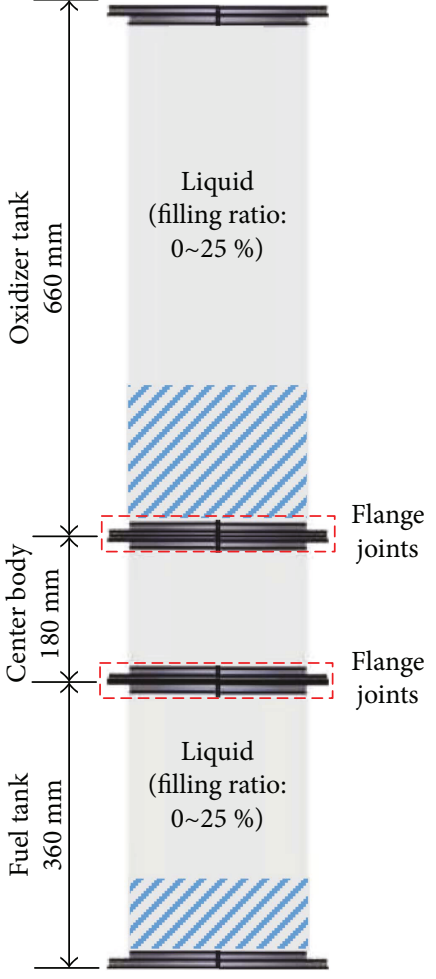

(a) Schematic diagram

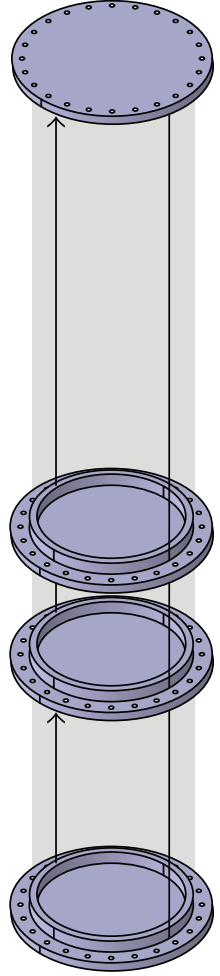

(b) 3D drawing

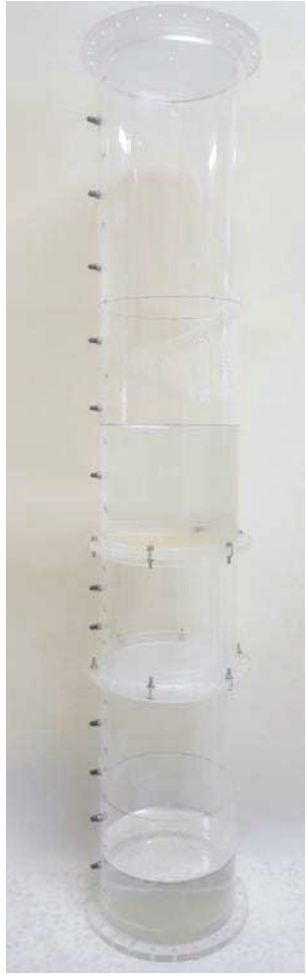

(c) Test model

FIgURE 1: Small-scale, first-stage model.

Flange joints connecting the section and the section (or the stage and stage) of space launch vehicles affect the stiffness of launch vehicle structures. Thus, the number of flange joints and their stiffness influence the modal characteristics of launch vehicles. Some computational structural analyses using the FE method have been performed for the flange joints of launch vehicles. The strength of flange joints for the KSLV- (Korea Space Launch Vehicle-) II was analyzed for their structural design [8]. The softening of flange joints under various loading conditions was investigated using the FE method [9]. However, there are limited studies on modal analyses for launch vehicles that include the modeling of flange joints.

The present study conducts modal tests and analyses of a small-scale, first-stage model of a space launch vehicle to establish FE modeling techniques for computational modal analyses, considering the liquid propellant and flange joints. The present launch vehicle model consists of an oxidizer tank, a center body, and fuel tank to represent the configuration of the first stage of launch vehicles that use liquid propellant. However, the small-scale, first-stage model in this work does not have dynamic similarity with the first stage of a full-scale launch vehicle because this work focuses on the establishment of FE modeling techniques for the liquid propellant and flange joints of launch vehicles; hence, the dynamic similarity between the small-scale model and fullscale model is not essential.

Modal tests for the launch vehicle model, which is made of acrylic, are conducted under the free-free boundary condition with different filling ratios of liquid (water) and various numbers of flange joints along the circumferential direction. Computational modal analyses are performed using the commercial FE analysis program, MSC.NASTRAN. The correlation between the modal tests and analyses, particularly for lateral bending modes, establishes FE modeling techniques for the liquid propellant and flange joints of space launch vehicles.

\section{Methods for Modal Tests and Analyses}

\subsection{Small-Scale, First-Stage Model of Space Launch Vehicles.} Figure 1 shows the simplified and scaled first-stage model of a space launch vehicle using liquid propellant. This model is composed of three sections: an oxidizer tank, a center body, and a fuel tank. The liquid propellant in an oxidizer tank and a fuel tank is modeled as water in this study. The geometric parameters of this model are obtained from the scaled values (4.59\%) of the first stage of the KSLV-II, which is currently under development. As previously mentioned, the dynamic similarities between the scaled and full-scale models are not considered. The scaled model is made of acrylic in order to facilitate the modal test in a small laboratory. As in the method used for a full-scale launch vehicle, all the sections of the scaled model are assembled using flange joints. In the modal tests, three cases with 6,12 , and 24 flange joints in the circumferential direction for each flange are considered to investigate the effects of the number of flange joints on modal characteristics. Each section consists of a body and flanges, as shown in Figure 2. The body is manufactured by processing an acrylic pipe with a thickness and diameter of 


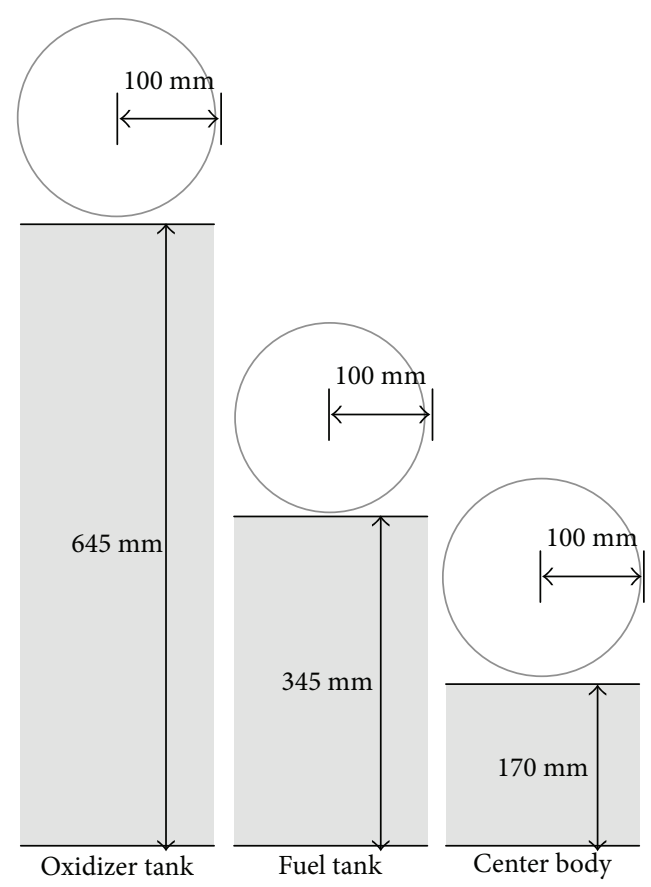

(a) Bodies

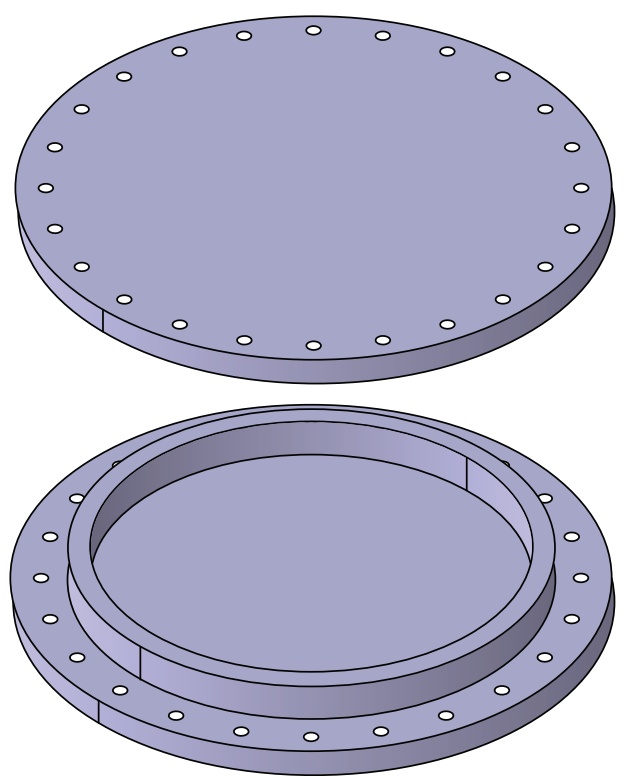

(b) Flanges

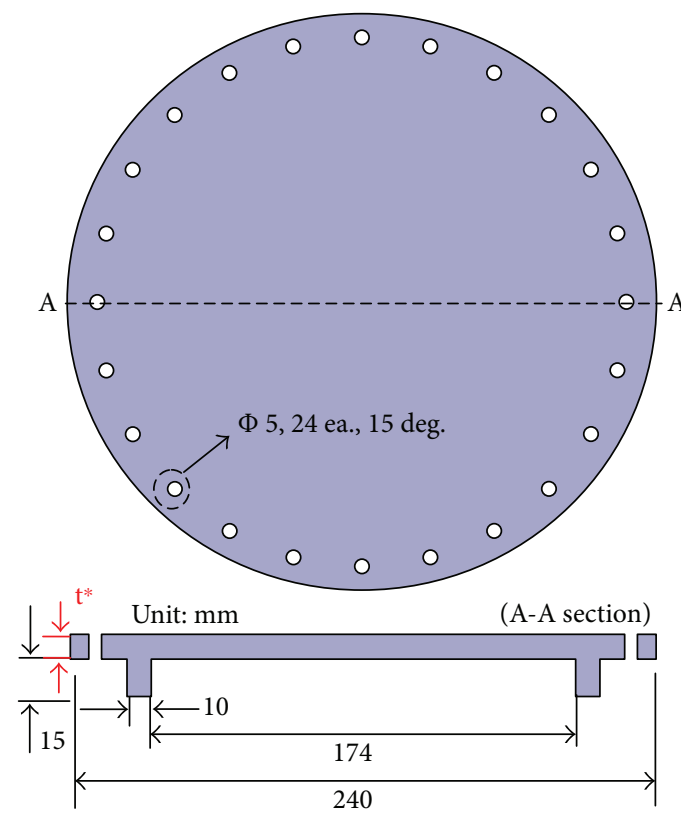

(c) Flange geometry parameters

Figure 2: Bodies and flanges of the test model.

TABLE 1: Geometric parameters of flanges $\left(t^{*}\right)$.

\begin{tabular}{lll}
\hline Oxidizer tank & Upper flange & $0.010 \mathrm{~m}$ \\
& Lower flange & $0.005 \mathrm{~m}$ \\
Center body & Upper flange & $0.005 \mathrm{~m}$ \\
\multirow{2}{*}{ Fuel tank } & Lower flange & $0.005 \mathrm{~m}$ \\
& Upper flange & $0.005 \mathrm{~m}$ \\
\hline
\end{tabular}

$0.003 \mathrm{~m}$ and $0.2 \mathrm{~m}$, respectively, and the flange is made of an acrylic plate. The detailed dimensions of the body and flange are given in Figures 2(a) and 2(c). The flange joint consists of a bolt, nut, and washer, all of which are made of steel use stainless. The holes, with a diameter of $0.005 \mathrm{~m}$ for the flange joints, are located at $15^{\circ}$ intervals in the circumferential direction; thus, there are 24 holes for each flange. Table 1 shows the dimensions of flange thickness. Four elastic ropes at the top of the oxidizer tank are used for the free-free boundary condition in the modal test; however, the ropes are not considered in the present FE modeling. 


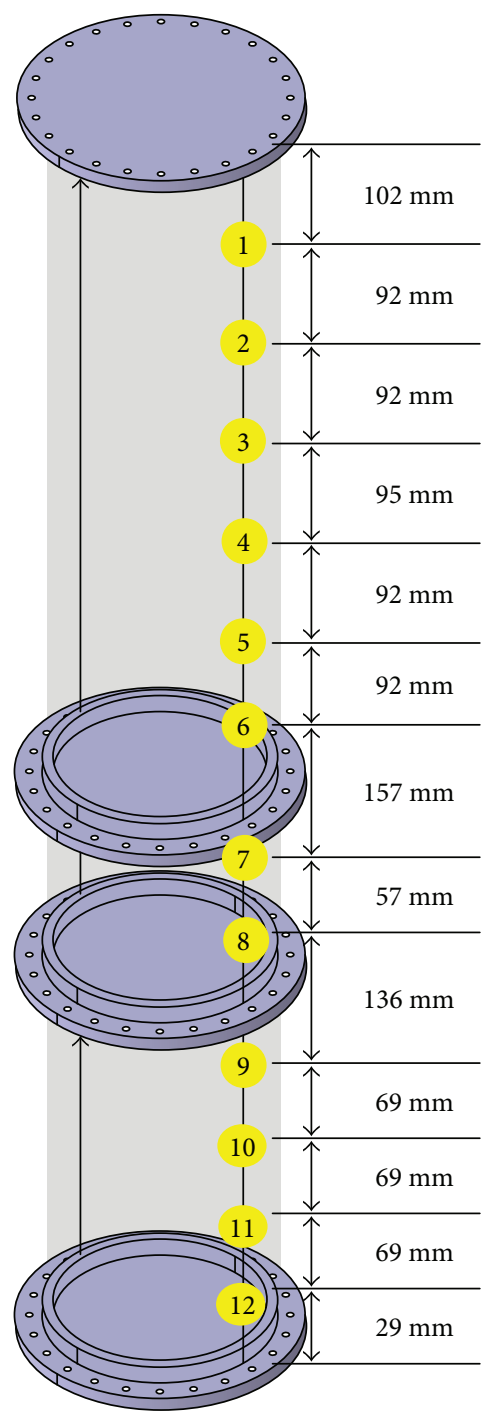

FIGURE 3: Locations of accelerometers.

TABLE 2: Weights of the components for a test model.

\begin{tabular}{lc}
\hline Oxidizer tank & $2350 \mathrm{~g}$ \\
Center body & $1101 \mathrm{~g}$ \\
Fuel tank & $1763 \mathrm{~g}$ \\
Nuts (48 ea.) & $50.4 \mathrm{~g}$ \\
Washers (96 ea.) & $29.8 \mathrm{~g}$ \\
Bolts (48 ea.) & $221.8 \mathrm{~g}$ \\
Elastic ropes (4 ea.) & $9.2 \mathrm{~g}$ \\
S-shaped rings (8 ea.) & $62.4 \mathrm{~g}$ \\
Total weight & $5600 \mathrm{~g}$ \\
\hline
\end{tabular}

To measure the natural frequencies and mode shapes in the bending modes of the present model containing liquid, accelerometers are located in the axial direction (Figure 3). The detailed weights of each part and the total weight of the scaled first-stage model, including the weights of the accelerometers, are summarized in Table 2.

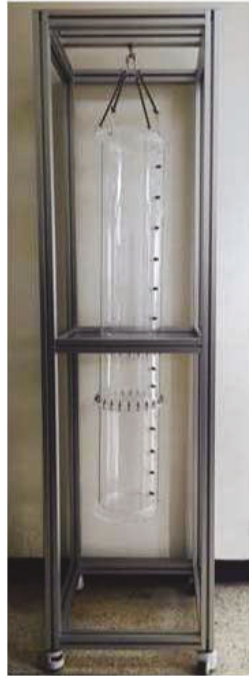

Figure 4: Small-scale, first-stage model for the modal test.

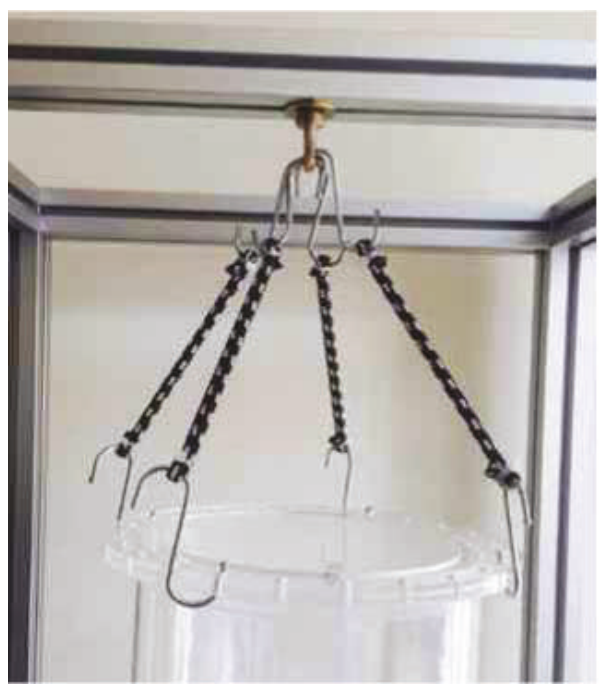

Figure 5: Four elastic ropes for the free-free boundary condition.

2.2. Experimental Setup for Modal Tests. Modal tests are conducted for the simplified and scaled first-stage model containing liquid (water) to measure the natural frequencies and mode shapes in lateral bending modes. As shown in Figures 4 and 5, this first-stage model is suspended vertically using elastic ropes. The oxidizer tank and fuel tank both contain water to represent the liquid propellant of a space launch vehicle, but the center body does not contain water. In this test performed in a small laboratory, two liquid filling ratios of $0 \%$ and $25 \%$ are used to take into account the available and safe weight of the test model containing water. It should be noted that the oxidizer tank and fuel tank contain the same amount of water (the same liquid filling ratio). However, the test stand structure may be at risk when the liquid filling ratio of each tank is higher than $50 \%$ in the present modal test, because of the weight of increased water. In addition, three cases with 

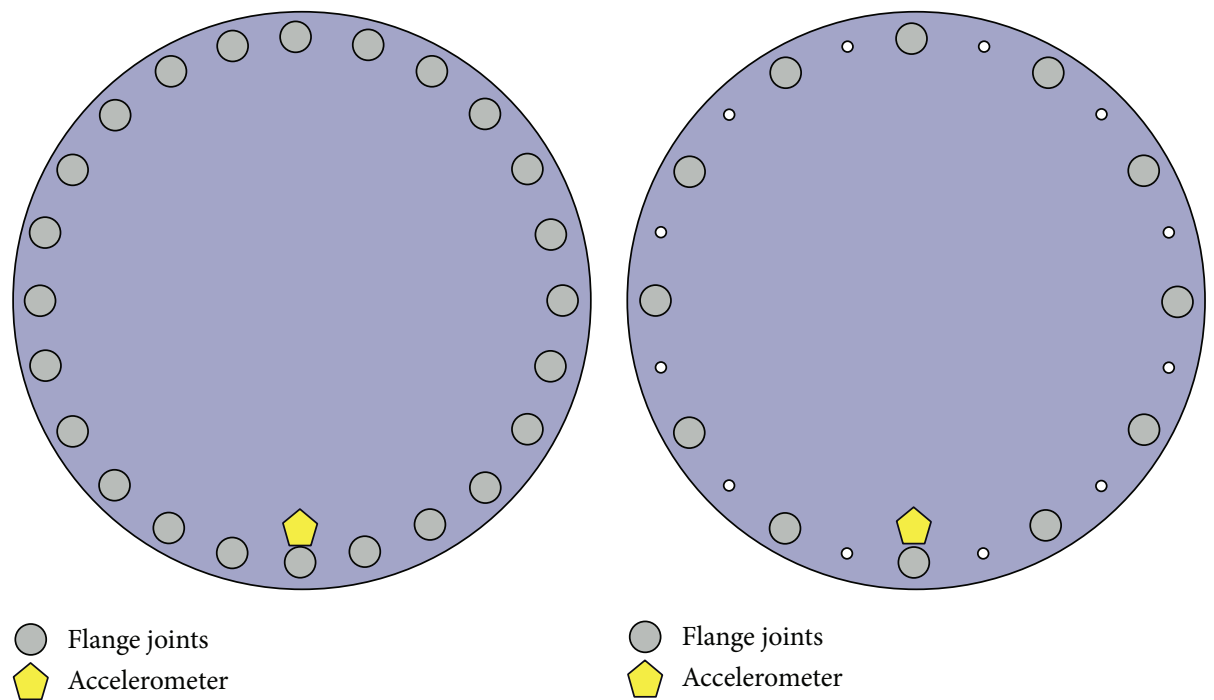

(a) Number of flange joints: 24 (interval: 15 deg.)

(b) Number of flange joints: 12 (interval: 30 deg.)

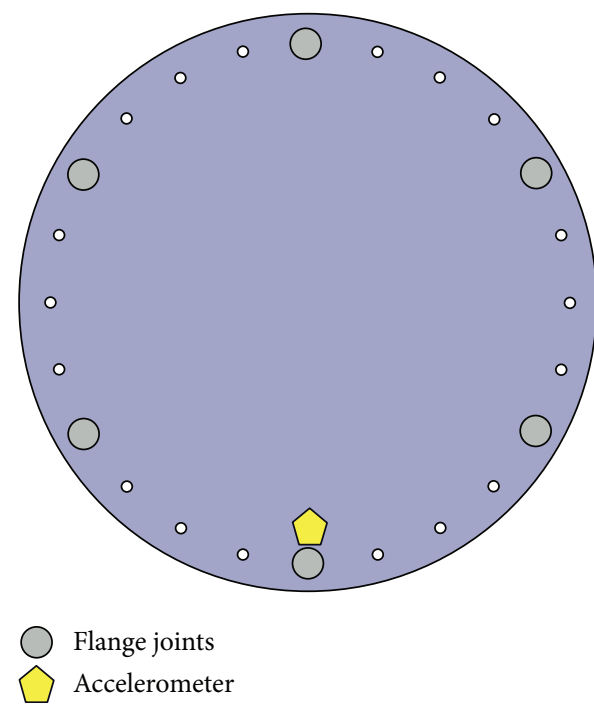

(c) Number of flange joints: 6 (interval: 60 deg.)

FIGURE 6: Locations and number of flange joints.

different numbers of flange joints are considered. Figure 6 shows the location of flange joints on the flange when the numbers of flange joints are 6, 12, and 24. In these figures, the yellow pentagon denotes the location of the accelerometer attached to the flange. Note that each flange uses the same number of flange joints.

The model in this modal test is excited using an impact hammer, and the dynamic behaviors are measured using 12 accelerometers attached along the axial direction (see Figure 3). The schematic diagram for the modal test is shown in Figure 7; the pictures and detailed information on the test equipment are summarized in Figure 8 and Table 3, respectively. The measured data from accelerometers in the time domain are converted into the data in the frequency domain using the FFT (fast Fourier transform) analysis to obtain the natural frequencies and mode shapes in lateral bending modes.
2.3. Finite Element Modeling for Modal Analyses. Computational modal analyses are conducted using MSC.NASTRAN, and its FE model is constructed by MSC.PATRAN. Figure 9 shows the FE model for the present first-stage model. The elastic modulus, Poisson's ratio, and density of acrylic for the modeling are $2.8 \mathrm{GPa}, 0.3$, and $1189 \mathrm{~kg} / \mathrm{m}^{3}$, respectively. The skins and flanges are modeled as shell elements. The distance between the shell element for the flange of the center body and the shell element for the flange of the oxidizer tank (or for the flange of a fuel tank) is modeled as $0.005 \mathrm{~m}$ (see Figure 10). The fastened flange joint is modeled using the one-dimensional spring element, the CBUSH element (see Figure 11). However, since the scaled first-stage model is quite small compared to the first-stage of the full-scale KSLV-II, the stiffness of the flange joint is underpredicted when only one node is used for modeling the flange joint. To solve this problem, the node-to-node connection is 


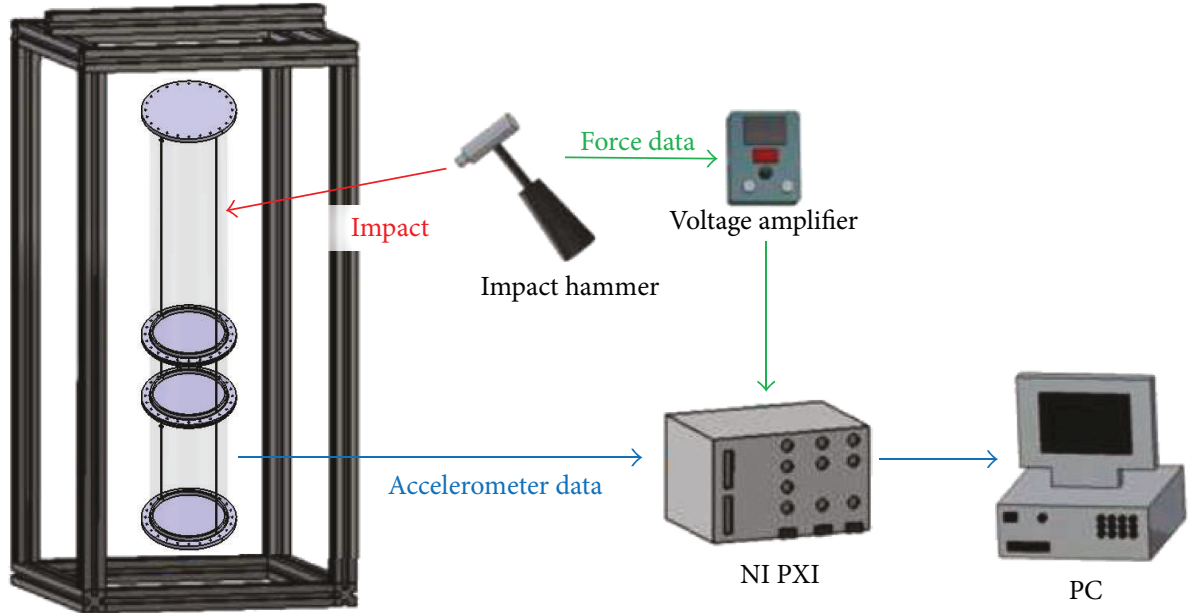

Figure 7: Schematic diagram of the modal test.

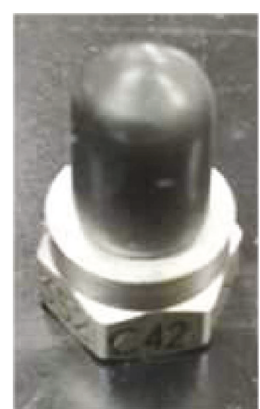

(a) Accelerometer (PCB 352C42)

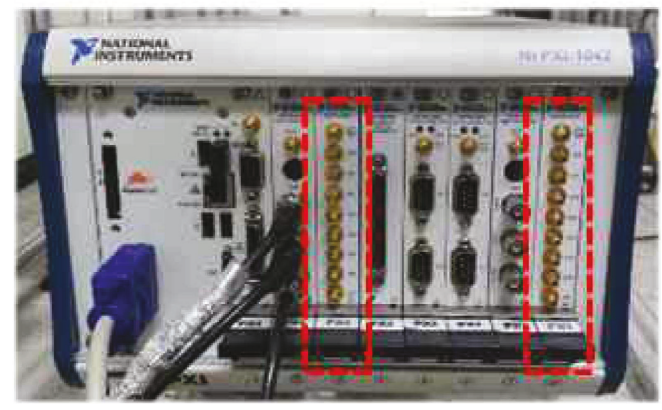

(c) NI PXI (NI-4472)

FIGURE 8: Equipment for the modal test.

additionally applied to the eight nodes around the single node for the fastened joint, as shown in Figure 12. The stiffness of the flange joint is modeled as the spring constant of the CBUSH element. When the liquid is not contained in the oxidizer and fuel tanks, the total number of finite elements used for the structural FE modeling not including spring elements is 24,672 . The oxidizer tank, center body, and fuel tank use 11,520, 5472, and 7680 finite elements, respectively, for the modeling. The total FE model of the present first-stage model is constructed by assembling of FE models using an appropriate number of finite elements for an oxidizer tank, a center body, and a fuel tank. Figure 13
TABLE 3: Specifications of test equipment.

(a) Accelerometer (PCB 352C42)

\begin{tabular}{lc}
\hline Sensitivity & $10.2 \mathrm{mV} / \mathrm{m} / \mathrm{s}^{2}$ \\
Broadband resolution (1 to $10,000 \mathrm{~Hz})$ & $\pm 491 \mathrm{~m} / \mathrm{s}^{2} \mathrm{pk}$ \\
Frequency range $( \pm 5 \%)$ & $0.005 \mathrm{~m} / \mathrm{s}^{2} \mathrm{rms}$ \\
Weight & 1 to $9000 \mathrm{~Hz}$ \\
Height, hex & $2.8 \mathrm{~g}$ \\
\hline
\end{tabular}

(b) Impact hammer (PCB 086C03)

\begin{tabular}{lc}
\hline Sensitivity & $2.28 \mathrm{mV} / \mathrm{N}$ \\
Measurement range & $\pm 2224 \mathrm{~N} \mathrm{pk}$ \\
Resonant frequency & $22 \mathrm{kHz}$ \\
Excitation voltage & 20 to $30 \mathrm{VDC}$ \\
Hammer mass & $0.16 \mathrm{~kg}$ \\
Tip type & Steel \\
\hline
\end{tabular}

(c) NI PXI (NI-4472)

\begin{tabular}{lc}
\hline Number of analog inputs & 8 \\
Resolution & $24 \mathrm{bits}$ \\
Sampling rate & $102.4 \mathrm{kS} / \mathrm{s}$ \\
Input range & $\pm 10 \mathrm{~V}$ \\
Dynamic range & $110 \mathrm{~dB}$ \\
\hline
\end{tabular}

shows the convergence of natural frequencies of each part (oxidizer tank, center body, and fuel tank) in terms of the number of finite elements. In the figure, the symbol $\mathrm{x}$ denotes the number of finite elements used for the present computations and corresponding natural frequencies of subparts. As seen in the figure, the present FE model provides the converged predictions on natural frequencies.

The liquid propellant of this launch vehicle model is represented as water in the FE modeling. For the modal analysis, the fluid (water) is modeled by the virtual mass method [10] 


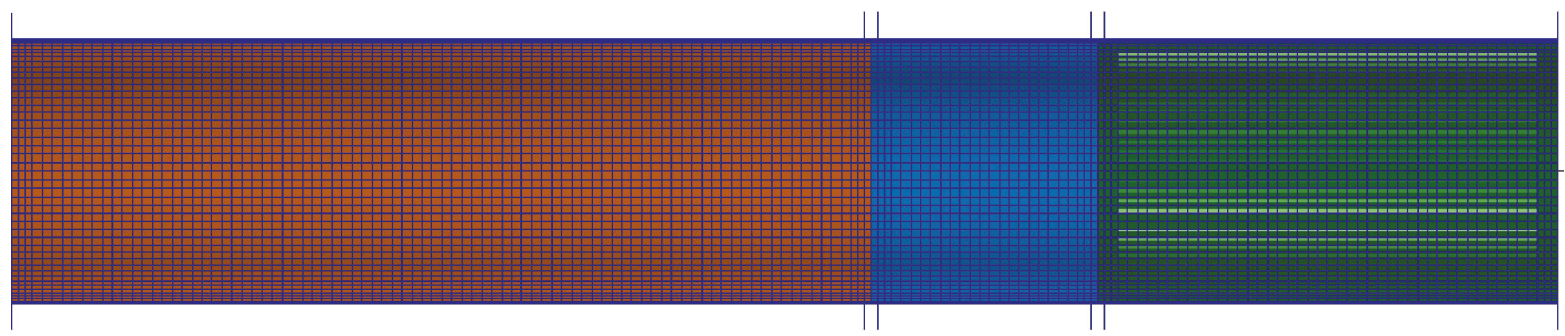

Figure 9: Finite element model for the small-scale, first-stage model.

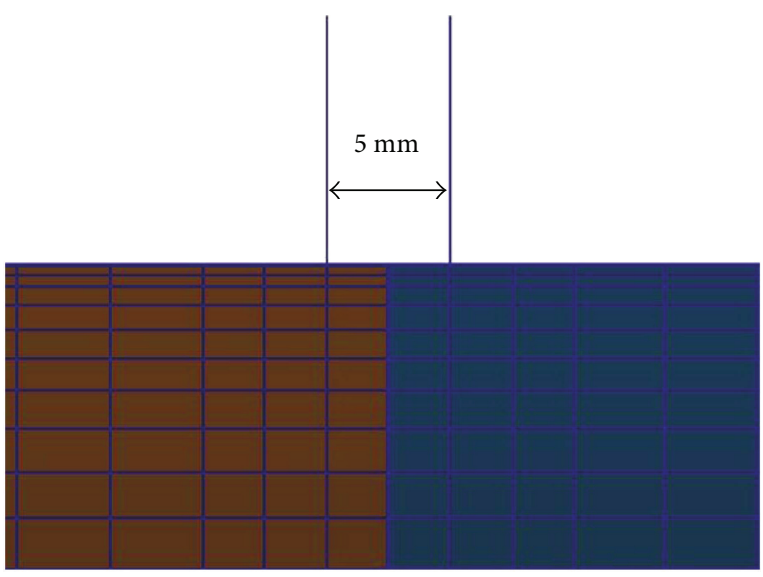

FIGURE 10: Distance modeling between two shell elements for flanges.

in MSC.NASTRAN. The virtual mass method considers the ideal fluid (incompressible, inviscid, and irrotational fluid). The fluid contained in the structure should have a free surface. The interface between fluids and structures can be modeled only as two-dimensional shell elements such as CQUAD4 or CTRIA3 elements. The frequency range of the structure containing the fluid, which would be analyzed, should be above the frequency range of sloshing modes.

\section{Results of Modal Tests and Analyses}

3.1. Modal Tests. For the case without water (filling ratio of $0 \%)$, modal tests are conducted to investigate the effects of the number of flange joints on modal characteristics. Three cases $(6,12$, and 24 flange joints for each flange) are considered, and only the first and second lateral bending modes are measured. Figure 14 gives the results of the modal tests with a liquid filling ratio of $0 \%$. As seen in the figure, the bending natural frequencies for the case with 6 flange joints are moderately or slightly lower than the natural frequencies of the other cases with 12 and 24 flange joints. That is, a greater number of flange joints correspond to higher bending natural frequencies. However, the natural frequencies for the cases with 12 and 24 flange joints are quite similar to each other. Figure 15 presents the modal test results when the liquid filling ratio is $25 \%$ and 24 flange joints per flange are used. Compared with the results in Figure 14, when the filling ratio increases from $0 \%$ to $25 \%$, the first and second bending natural frequencies decrease by $20 \%$ and $12 \%$, respectively,
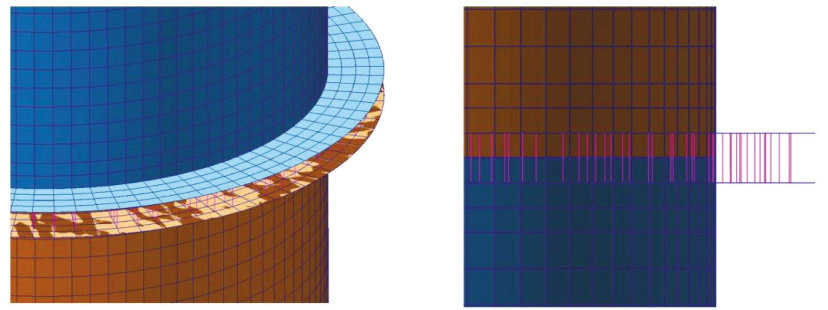

FIgURE 11: Fastened flange joint modeling using one-dimensional spring elements.

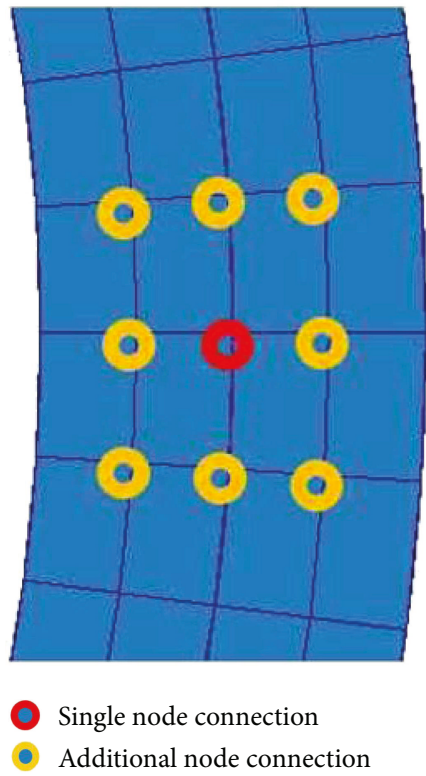

FIGURE 12: Locations of node-to-node connection.

since an increase in mass reduces the natural frequencies of the test model. Finally, Table 4 summarizes the measured natural frequencies in the first and second lateral bending modes from the modal tests.

3.2. Computational Modal Analyses. Figure 16 shows the calculated natural frequencies and mode shapes in the first lateral bending modes without water (liquid filling ratio of $0 \%$ ), when different spring constants of the CBUSH element are considered and 24 flange joints are used per flange. As seen in the figure, the spring constant of the CBUSH element 


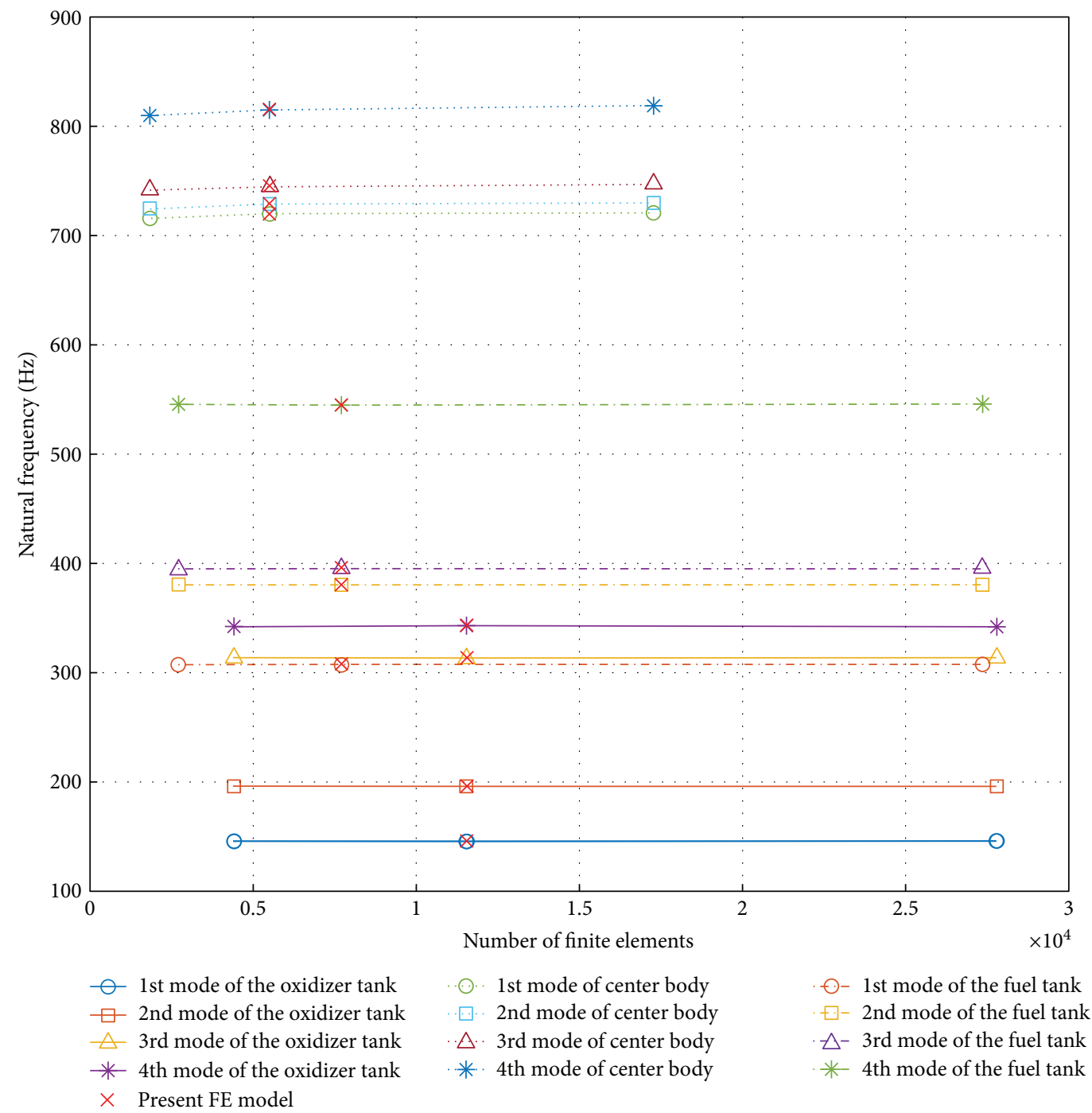

FIGURE 13: Convergences of natural frequencies in terms of the number of finite elements.

has a significant effect on the natural frequency. As the spring constant increases, the natural frequency in the first bending mode increases since the stiffness of the structure increases. However, when the spring constant is above $10^{18} \mathrm{~N} / \mathrm{m}$, the lateral bending modes are not predicted in the present computation. When the predicted results are compared with the measured data from the modal test in the previous section, it is concluded that a spring constant of $10^{10} \mathrm{~N} / \mathrm{m}$ is reasonably appropriate for the present analyses. Thus, the spring constant of $10^{10} \mathrm{~N} / \mathrm{m}$ is used for all the remaining calculations in this work. In the computational modal analyses for the liquid filling ratio of $0 \%$ and 24 flange joints per flange, the first and second lateral bending modes correspond to the first and ninth modes of the total modes, respectively. Many modes between two lateral bending modes represent the local modes such as shell modes of the present launch vehicle structure model. However, this study focuses on the first and second lateral bending modes only.

Figure 17 presents the predicted natural frequencies in the first and second bending modes when the numbers of flange joints for each flange are 6,12 , and 24 and the liquid filling ratio is $0 \%$. The natural frequencies increase as the number of flange joints per flange increases. In both lateral bending modes, the rate of increase in the natural frequency when the number of flange joints increases from 6 to 12 is higher than that when the number of flange joints increases from 12 to 24 .

Figure 18 shows the calculated natural frequencies and mode shapes in the bending modes for the case with 24 flange joints and a liquid filling ratio of $25 \%$. Compared with the previous calculations without water in Figure 16, the predicted natural frequencies decrease by $10.1 \%$ and $6.4 \%$ in the first and second bending modes, respectively. The predicted natural frequencies for 24 flange joints and the filling ratio of $50 \%$ are given in Figure 19. Figure 20 shows the change in the predicted natural frequencies in the first and second bending modes in terms of the liquid filling ratio. As seen in the figure, the decrease in the natural frequency in the second bending mode is more obvious than that in the first bending mode. When the liquid filling ratio is above $50 \%$, the computational modal analysis cannot be conducted due to the limitation of the computer memory (RAM). 

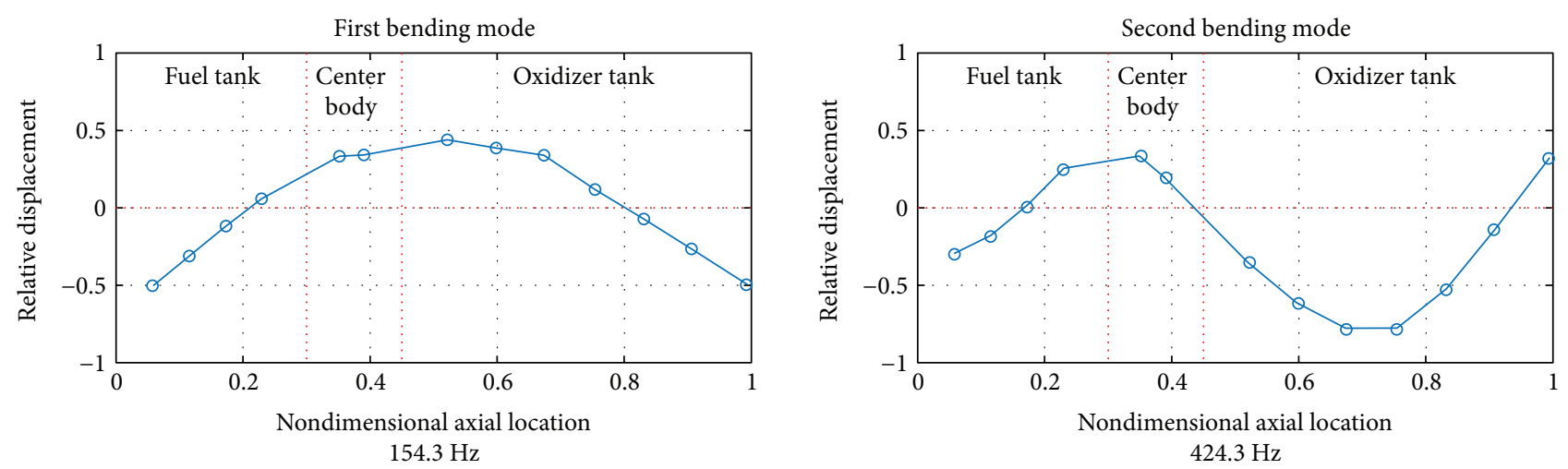

(a) Number of flange joints: 24
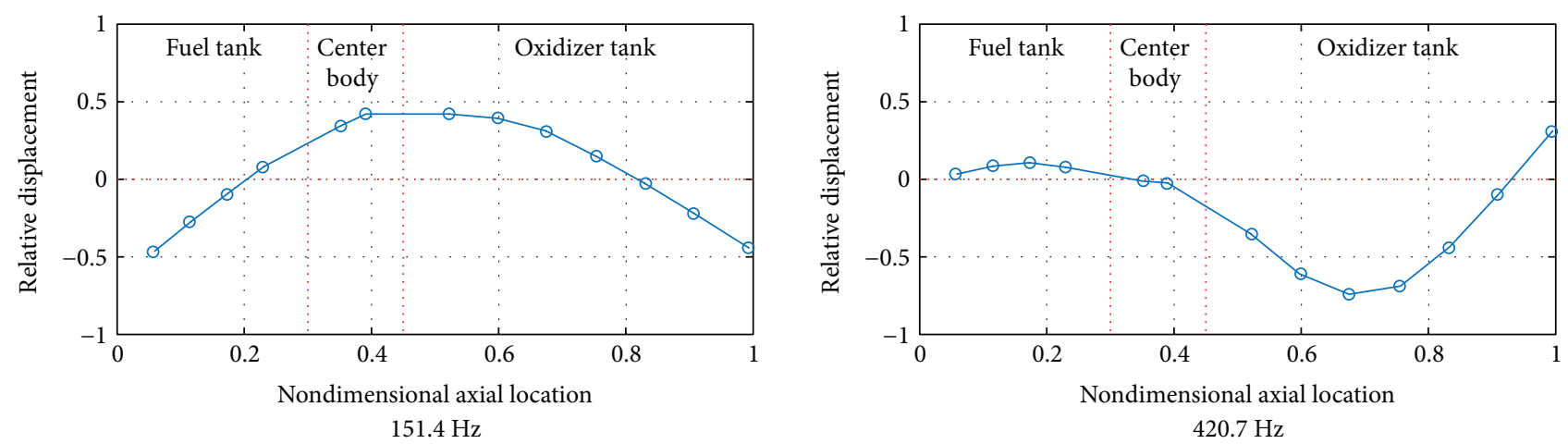

(b) Number of flange joints: 12
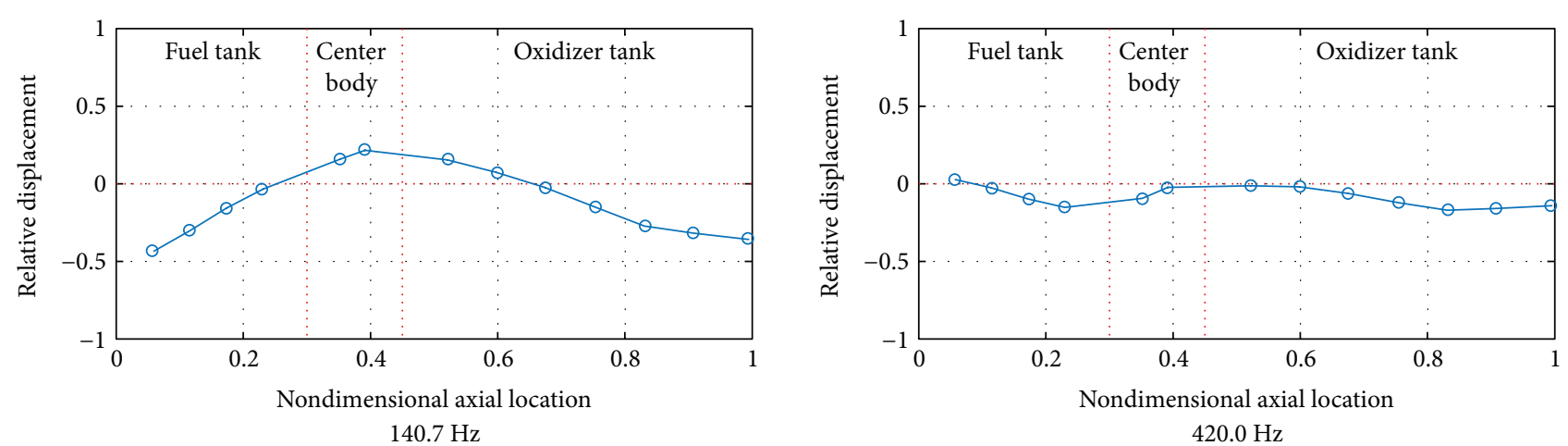

(c) Number of flange joints: 6

FIGURE 14: Modal test results for the filling ratio of $0 \%$.

3.3. Correlation between Tests and Analyses. The correlations between the modal tests and analyses using the measured and predicted results are given in Tables 5 and 6 . For the case of the filling ratio of $0 \%$, as seen in Table 5, the comparison between the modal test and analysis results shows good agreements for the case of 24 flange joints for each flange. However, when the number of flange joints is lower (12 or 6 ), the correlation is not as good as that of the case with 24 flange joints per flange. In addition, as the number of flange joints decreases, the relative error increases. It is noteworthy that all the measured natural frequencies are higher than the predicted values since the present modal test using elastic ropes cannot model perfectly the free-free boundary condition, which gives a stiffer boundary condition than the ideal free-free boundary condition. Table 6 presents the correlation between the test and computational results when the liquid filling ratio is $25 \%$. In this correlation, the number of flange joints per flange is 24 . The relative errors are within $10 \%$ for both lateral bending modes; therefore, the present modal analyses reasonably predict the natural frequencies in the bending modes of the simplified and scaled firststage model of a launch vehicle.

\section{Conclusions}

In this study, modal tests and analyses were conducted for the simplified and scaled first-stage model of a space launch vehicle using liquid propellant in order to establish FE 
First bending mode

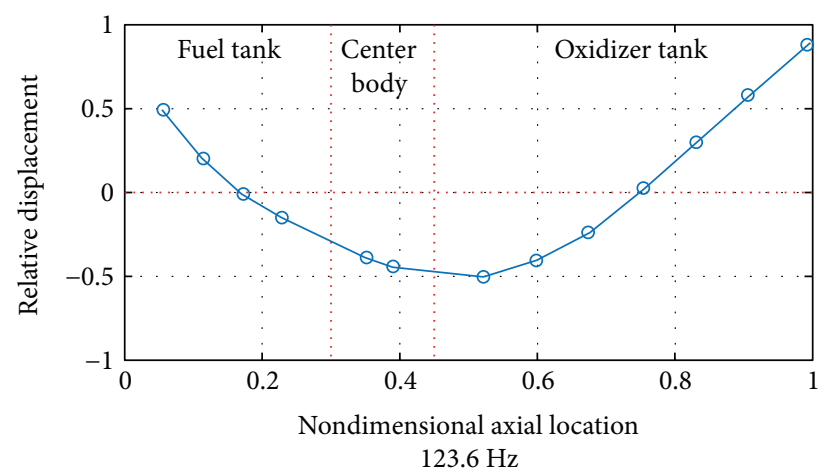

Second bending mode

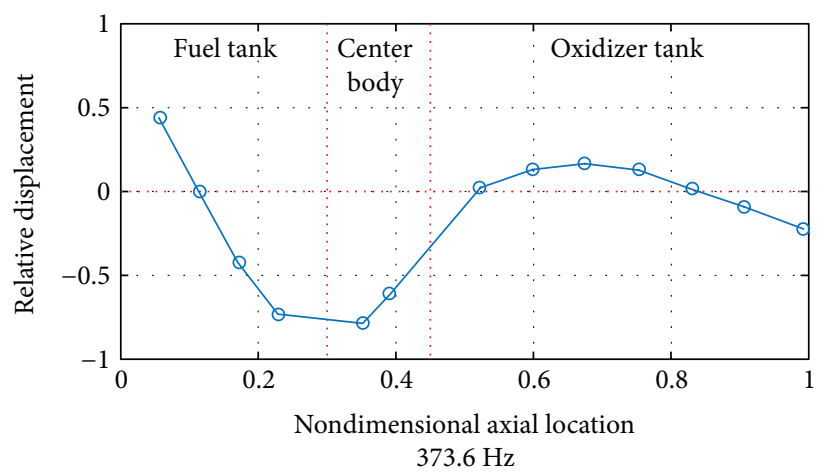

FIgURE 15: Modal test results for the filling ratio of $25 \%$ and 24 flange joints per flange.

TABLE 4: Summary of the measured natural frequency (modal test results).

\begin{tabular}{lcccc}
\hline Filling ratio & \multicolumn{3}{c}{$0 \%$} & $25 \%$ \\
\hline Number of flange joints & 24 & 12 & 6 & 24 \\
First bending mode & $154.3 \mathrm{~Hz}$ & $151.4 \mathrm{~Hz}$ & $140.7 \mathrm{~Hz}$ & $123.6 \mathrm{~Hz}$ \\
Second bending mode & $424.3 \mathrm{~Hz}$ & $420.7 \mathrm{~Hz}$ & $420.0 \mathrm{~Hz}$ & $373.6 \mathrm{~Hz}$ \\
\hline
\end{tabular}

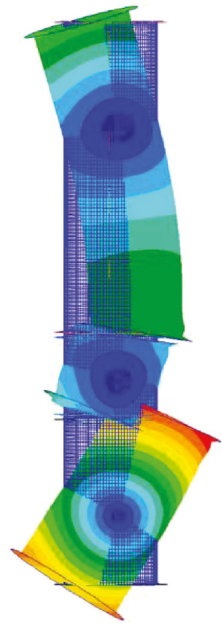

$135.1 \mathrm{~Hz}$

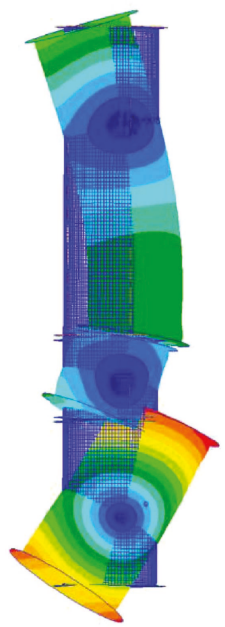

$149.4 \mathrm{~Hz}$

(b) Spring constant: $10^{10} \mathrm{~N} / \mathrm{m}$

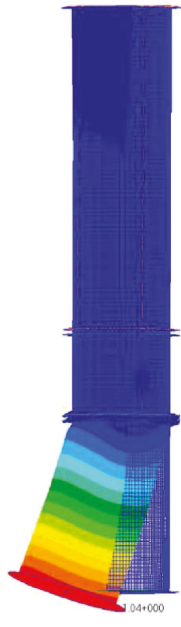

$176.9 \mathrm{~Hz}$

(c) Spring constant: $10^{18} \mathrm{~N} / \mathrm{m}$
FIGURE 16: The predicted first bending modes in terms of the spring constant (liquid filling ratio: $0 \%$ ).

modeling techniques for the liquid propellant and flange joints of a space launch vehicle.

For the scaled model composed of an oxidizer tank, a center body, and a fuel tank, the modal tests measured the natural frequencies and mode shapes in the first and second lateral bending modes. In the tests, the effects of the liquid filling ratio and number of flange joints were investigated. Computational modal analyses using the FE method were conducted. The liquid in the oxidizer and fuel tanks was modeled using the virtual mass method, and the flange joints were modeled using the one-dimensional spring elements

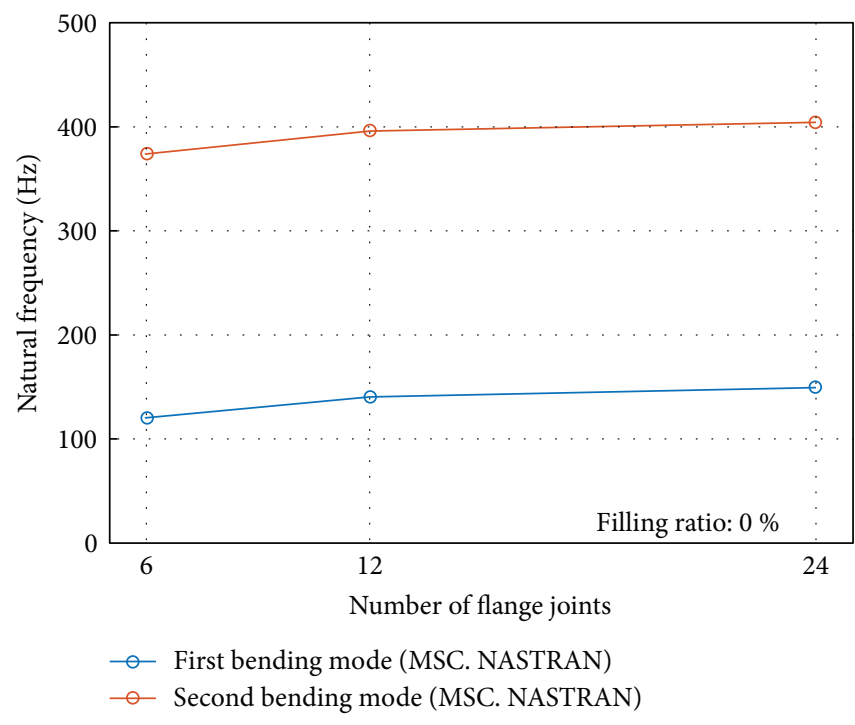

FIgURE 17: The predicted bending natural frequencies in terms of the number of flange joints (liquid filling ratio: $0 \%$ ).

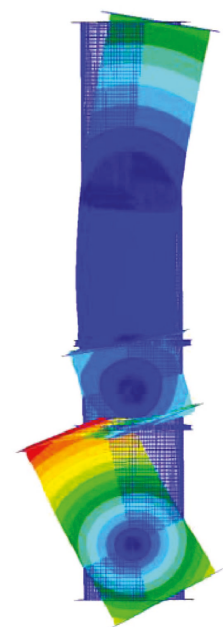

First bending mode $134.3 \mathrm{~Hz}$

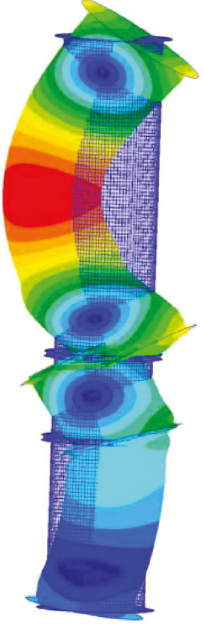

Second bending mode $378.3 \mathrm{~Hz}$
Figure 18: Modal analysis results for the liquid filling ratio of $25 \%$ and 24 flange joints per flange. 


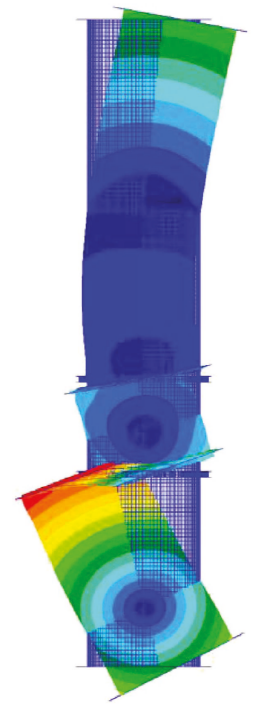

First bending mode $131.7 \mathrm{~Hz}$

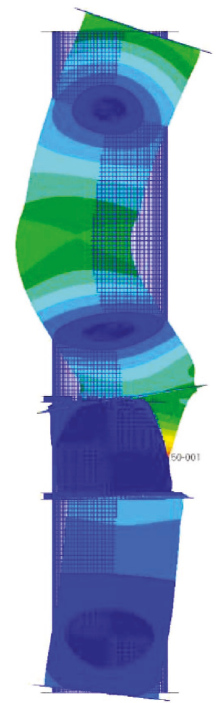

Second bending mode $296.5 \mathrm{~Hz}$
FIGURE 19: Modal analysis results for the liquid filling ratio of $50 \%$ and 24 flange joints per flange.

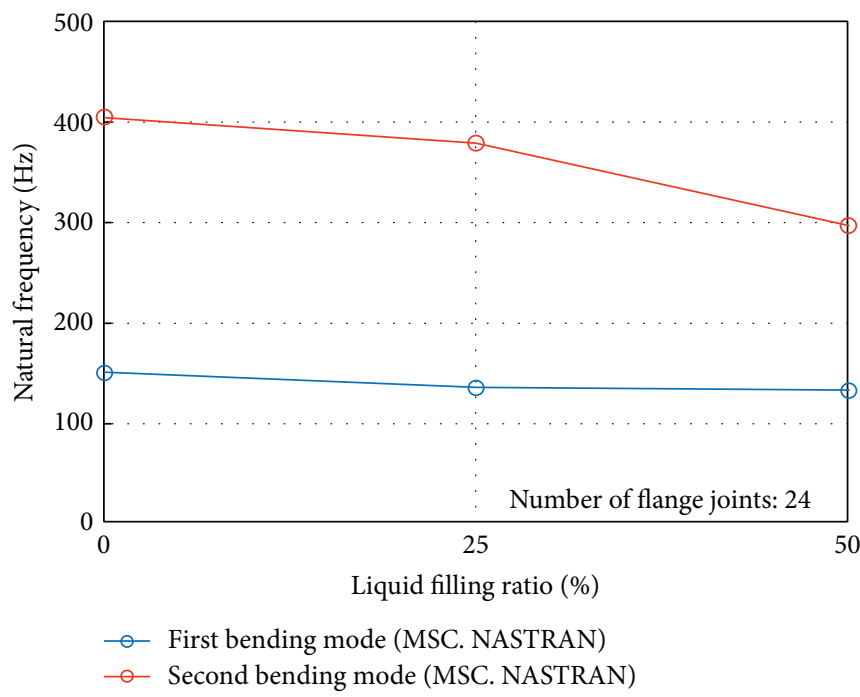

FIGURE 20: The predicted bending natural frequencies in terms of the liquid filling ratio.

along with the node-to-node connection. The shell elements were used for the FE modeling of skins and flanges.

In both the modal tests and analyses, as the number of flange joints increased, the bending natural frequencies increased. In addition, when the liquid was contained in the oxidizer and fuel tanks, the natural frequencies decreased. The measured and predicted natural frequencies in the first and second bending modes were correlated. When the number of flange joints for each flange was 24, the present analyses predicted the bending natural frequencies relatively well for the cases with and without liquid, as compared with the measured values. However, when the number of flange joints
TABLE 5: Modal tests and analysis results (filling ratio: 0\%).

\begin{tabular}{lcc}
\hline Modes & $\begin{array}{c}\text { First bending } \\
\text { mode }(\mathrm{Hz})\end{array}$ & $\begin{array}{c}\text { Second bending } \\
\text { mode }(\mathrm{Hz})\end{array}$ \\
\hline Number of flange joints: 24 & & \\
Modal test & 154.3 & 424.3 \\
MSC.NASTRAN & 149.4 & 404.2 \\
Error (\%) & -3.18 & -4.74 \\
\hline Number of flange joints: 12 & & \\
Modal test & 151.4 & 420.7 \\
MSC.NASTRAN & 140.5 & 395.8 \\
Error (\%) & -7.20 & -5.92 \\
\hline Number of flange joints: 6 & & \\
Modal test & 140.7 & 420.0 \\
MSC.NASTRAN & 120.5 & 373.9 \\
Error (\%) & -14.36 & -10.98 \\
\hline
\end{tabular}

TABLE 6: Modal test and analysis results (filling ratio: 25\%; number of flange joints: 24 ).

\begin{tabular}{lcc}
\hline Modes & $\begin{array}{c}\text { First bending } \\
\text { mode }(\mathrm{Hz})\end{array}$ & $\begin{array}{c}\text { Second bending } \\
\text { mode }(\mathrm{Hz})\end{array}$ \\
\hline Modal test & 123.6 & 373.6 \\
MSC.NASTRAN & 134.3 & 378.3 \\
Error (\%) & 8.65 & 1.26 \\
\hline
\end{tabular}

was lower (12 or 6), the correlation was not as good as that of the case of 24 flange joints per flange.

Through the present work, the techniques for FE modeling and analysis were established for the computational modal analysis of space launch vehicles using liquid propellant.

\section{Conflicts of Interest}

The authors declare that there is no conflict of interest regarding the publication of this paper.

\section{Acknowledgments}

This work was supported by the Korea Space Launch Vehicle (KSLV-II) funded by the Ministry of Science, ICT and Future Planning (MSIP, Korea).

\section{References}

[1] R. P. Miller and T. F. Gerus, Experimental Lateral Bending Dynamics of the Atlas-Centaur-Surveyor Launch Vehicle, NASA TM X-1837, Washington, DC, 1969.

[2] S. H. Youn, Y. S. Jang, S. H. Park, and Y. M. Yi, "Modal test of EM (engineering model) and modal analysis of FM (flight model) for KSR-III," Journal of The Korean Society for Aeronautical \& Space Sciences, vol. 34, no. 2, 2004.

[3] R. D. Buherle, J. D. Templeton, M. C. Reaves et al., "ARES I-X launch vehicle modal test overview," in Proceedings of the IMAC-XXVIII, Jacksonville, Florida, 2010. 
[4] T. Mazuch, J. Horacek, J. Trnka, and J. Vesely, "Natural modes and frequencies of a thin clamped-free steel cylindrical storage tank partially filled with water: FEM and measurement," Journal of Sound and Vibration, vol. 193, no. 3, pp. 669-690, 1996.

[5] S. Qiu, "Dynamic analysis of composite overwrap pressure vessel, M.S. thesis," Department of Mechanical Engineering, Vanderbilt University, Nashville, Tennessee, 2004.

[6] F. Sabri and A. A. Lakis, "Hydroelastic vibration of partially liquid-filled circular cylindrical shells under combined internal pressure and axial compression," in Proceedings of the 50th AIAA/ASME/ASCE/AHS/ASC Structures, Structural Dynamics, and Materials Conference, Palm Springs, California, 2009.

[7] H. Jalali and F. Parvizi, "Experimental and numerical investigation of modal properties for liquid-containing structures," Journal of Mechanical Science and Technology, vol. 26, no. 5, pp. 1449-1454, 2012.

[8] G. S. Kim, Y. S. Jang, and Y. M. Lee, "Design and analysis of KSLV-II section bolt flange joints," in Proceedings of the Korean Society for Aeronautical \& Space Sciences Spring Conference, Gangwon-do, Republic of Korea, 2013.

[9] G. M. Henson and B. A. Hornish, "An evaluation of common analysis methods for bolted joints in launch vehicles," in Proceedings of 51st AIAA/ASME/ASCE/AHS/ASC Structures, Structural Dynamics, and Materials Conference, Orlando, Florida, 2010.

[10] W. Johannes, The virtual mass method, Virtual Mass Seminar, MSC Corporation, 2002. 


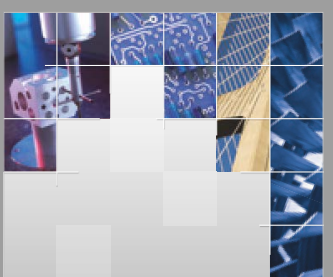

\section{Enfincering}
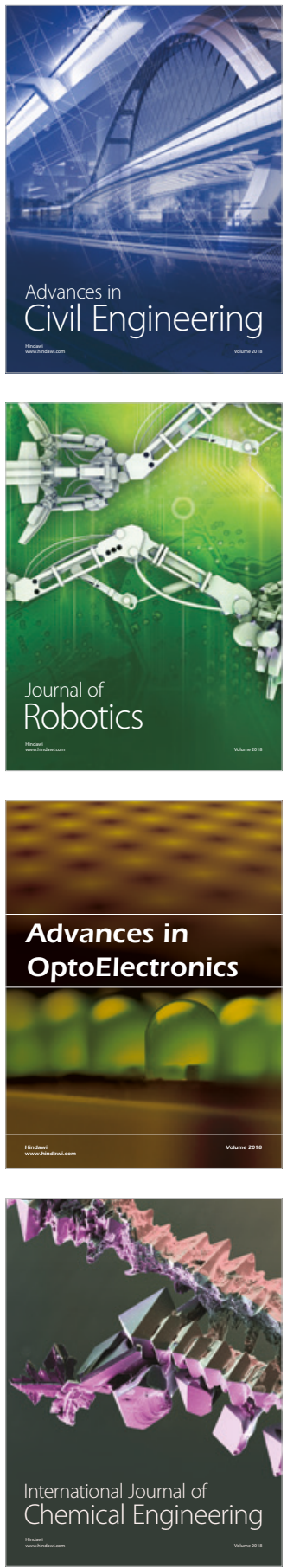

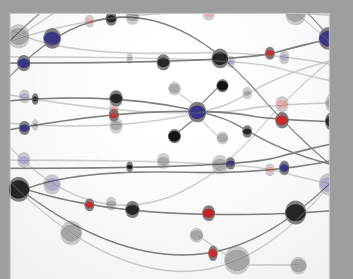

\section{Rotating \\ Machinery}

The Scientific World Journal

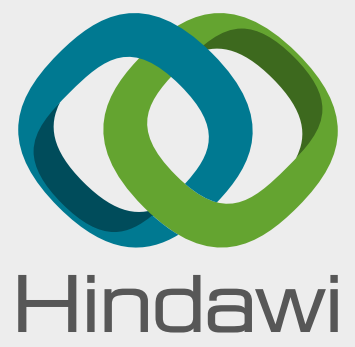

Submit your manuscripts at

www.hindawi.com
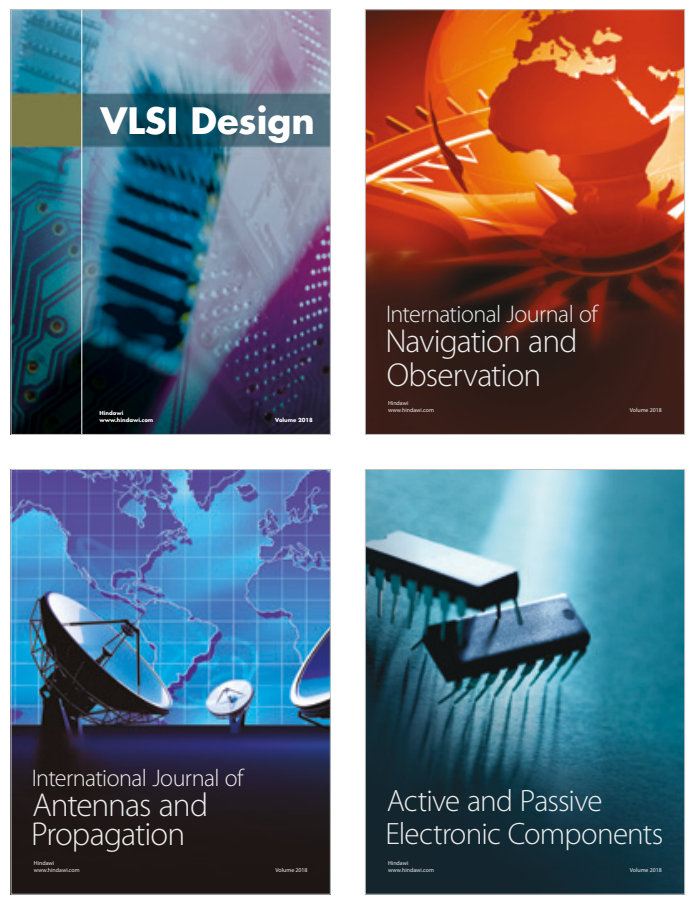
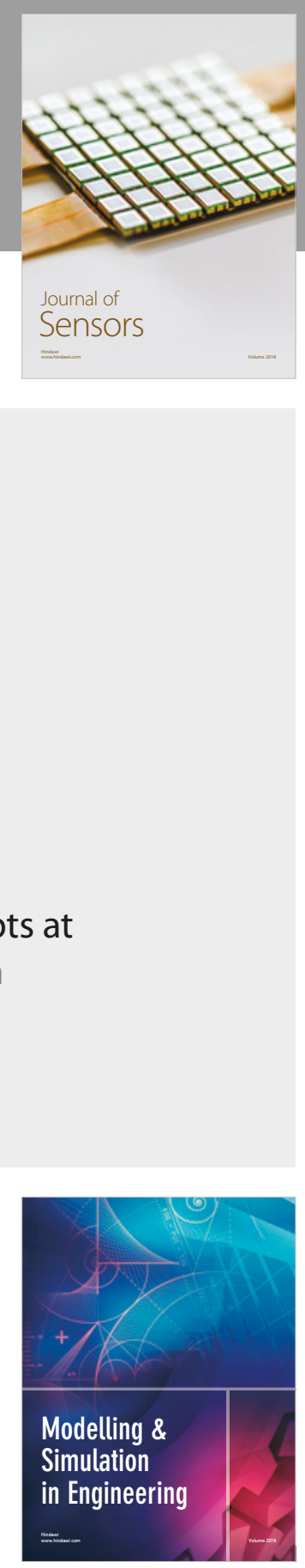

\section{Advances \\ Multimedia}
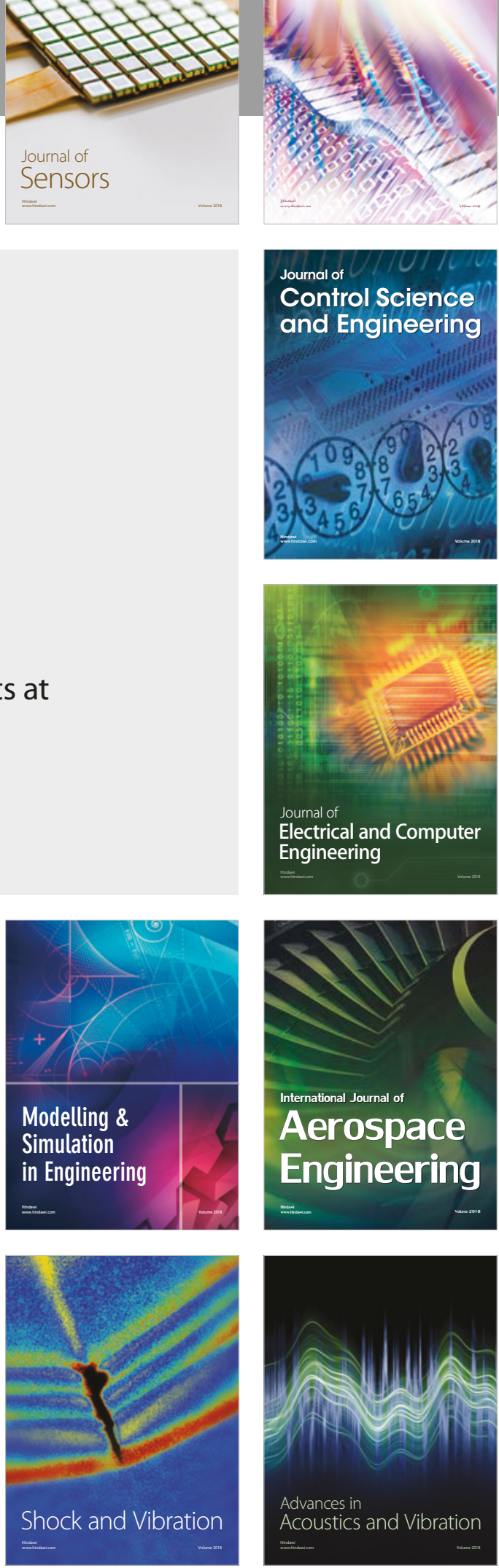